\title{
SEGURANÇA DA INFORMAÇÃO COM FOCO EM INFRAESTUTURA: UM ESTUDO DE CASO EM UM ORGÃO PÚBLICO
}

Gustavo Catucci Rego, Helton Molina Sapia, Haroldo Cesar Alessi, Dione Jonathan Ferrari, Rogério Marcus Alessi, Glauco Antonio Ruiz, Marcelo Vinicius Creres Rosa.

Universidade do Oeste Paulista - UNOESTE, Especialização em MBA em TI, Presidente Prudente, SP, E-mail: Gustavo catucci@hotmail.com.

\section{RESUMO}

Este trabalho teve como objetivo analisar a infraestrutura de uma organização (órgão público) no aspecto da segurança da informação e propor melhorias para a mesma. Foram considerados principalmente os três princípios essenciais da segurança da informação: confidencialidade, integridade, disponibilidade. A pesquisa é um estudo de caso, pois trata da identificação da criticidade de falhas dentro de um ambiente real, tanto na parte de infraestrutura quanto funcional da empresa. Os procedimentos possuem duas etapas, a primeira foi a obtenção dos requisitos essenciais para o desenvolvimento e evolução do estudo; e a segunda, foi a proposta de melhoria da infraestrutura e avaliação dos resultados. Por fim, apresenta-se uma visão geral dos resultados obtidos pelo desenvolvimento desse estudo de caso, propondo e mostrando as mudanças que podem ser realizadas para melhorar a segurança da informação, como também os serviços dos demais setores da empresa, caso forem implantadas de forma gradual.

Palavras-chave: Segurança da Informação, Infraestrutura, Estudo de Caso.

\section{INFORMATION SECURITY WITH FOCUS ON INFRASTRUCTURE: A CASE STUDY AT A PUBLIC AGENCY}

\begin{abstract}
This work aimed to analyze the infrastructure of the company (public agency) in the information security aspect and propose improvements to it. Taking into account the three essential principles of information security (confidentiality, integrity, availability). The research is a case study, since it deals with the identification of the criticality of failures within a real environment, both in the infrastructure and functional part of the company. The procedures have two stages, the first being the achievement of the essential requirements for the development and evolution of the study; And the second is the proposal for improving infrastructure and evaluating results. Finally, an overview of the results obtained by the development of this case study is presented, suggesting and showing the changes that can be made to improve information security, as well as the services of the other sectors of the company, if implemented in a way gradual.
\end{abstract}

Keywords: Information Security, Infrastructure, Case Study. 


\section{INTRODUÇÃO}

Não é de hoje que surgem certos episódios envolvendo vazamento de informações, crimes organizados e espionagem dentro de setores públicos, empresas e organizações em gerais.

Conforme DANTAS (2011), em fevereiro de 2008, uma das maiores empresas petrolíferas do mundo teve computadores portáteis furtados com informações estratégicas de uma reserva gigante, descoberta no ano anterior, estimada em torno de 8 bilhões de barris de petróleo, sendo considerada uma das maiores descobertas de petróleo dos últimos anos. As notícias sobre esse evento ocuparam as principais manchetes na mídia mundial, além de exporem a fragilidade da segurança da informação em uma empresa multinacional, o que provocou a apreensão dos seus acionistas. Este acontecimento reflete a questão da segurança da informação, o quanto é complexa e como deve ser prestada mais atenção em cada detalhe.

Atualmente, a segurança da informação exige um melhor preparo e mais atenção para diminuir ao máximo a perda da informação e os riscos de vazamento das mesmas.

As empresas utilizam cada vez mais como instrumento a informática e as principais tecnologias da informação dentro delas, onde procuram realizar seus trabalhos de forma mais rápida, eficiente e mais competitiva. A rede de computadores, uma das principais tecnologias em uso, permite conexões entre equipamentos que acessam sistemas importantes como, por exemplo, sistemas financeiros. $O$ acesso das informações segue desde roteadores a servidores com o banco de dados da empresa e websites hospedados em servidores externos. Ainda, dentro das empresas ocorre o uso abusivo da internet pelos colaboradores, onde por exemplo: utilizam para fins pessoais e realizando todo tipo de downloads em sua estação de trabalho. Esse cenário favorece diariamente o surgimento de diferentes tipos de ataques, e com pequenos descuidos ou ações furtivas podem facilitar a execução do crime cibernético.

As informações são consideradas também patrimônio das empresas, onde se encontram em constante risco; com isso, a segurança da informação se torna crucial para a sobrevivência das mesmas.

Segundo CARVALHO (2013), o problema da segurança está relacionado nas vulnerabilidades na qual não foram tratadas, ou seja, softwares desatualizados, produtos, hardwares mal configurados, profissionais com treinamento falho ou sem treinamento, funcionários sem comprometimento e a falta de instruções, boas práticas na empresa, ordens (política de segurança).

Baseado nesses dados fica claro a necessidade da criação e implantação de uma infraestrutura de TI que contemple a segurança da informação dentro das organizações. O estudo dessa infraestrutura de TI foi realizado em uma organização existente, sendo um órgão público, o posto de saúde do munícipio de Álvares Machado (UBS II - Unidade Básica de Saúde).

O objetivo deste estudo foi apresentar orientações sobre como criar e implantar uma infraestrutura de TI (Tecnologia da Informação) que forneça a segurança da informação da UBS II. Sendo assim, este estudo foi realizado com o auxilio das normas ABNT NBR ISO/IEC da série 27000, mais precisamente a norma ISO/IEC 27002.

Pode-se considerar alguns objetivos específicos para realização deste estudo de caso: (1) Apresentar a Segurança da Informação e sua importância dentro do ambiente organizacional; (2) Apresentar resumidamente as normas da série 27000 , com foco na norma ISO/IEC 27002; (3) Fazer uma análise da organização e levantar informações; (4) Identificar os problemas do local em relação a infraestrutura de $\mathrm{Tl}$; (5) Fazer a análise de riscos e vulnerabilidades da organização; (6) Analisar e observar os fatores críticos de sucesso da segurança da informação na organização relativos a infraestrutura de $\mathrm{TI}$, e propor melhorias; (7) Resultado e conclusões gerais. 


\section{METODOLOGIA}

Este capítulo descreve a metodologia usada no trabalho e que possibilitou que fossem alcançados os objetivos do estudo. O desenvolvimento deste trabalho foi realizado na UBS II de Álvares Machado, onde foi feito o levantamento e análise inicial da mesma. Nessa etapa, pretendeu-se identificar as dificuldades, problemas e vulnerabilidades da organização quanto à segurança da informação.

Quanto à natureza da pesquisa, ela pode ser caracterizada como aplicada ou tecnológica, pois tem como finalidade aplicar conhecimentos adquiridos durante o curso, e formular uma nova infraestrutura para o processo de segurança da informação para a UBS II. Sendo realizada também, uma observação em campo e entrevistas com colaboradores da organização para levantamento das deficiências estruturais e funcionais, ou seja, levantar as falhas tanto da infraestrutura como de segurança da informação, sendo elas funcionais e/ou estruturais.

As propostas de melhorias tiveram como base a ABNT NBR ISO/IEC 27002 sobre a parte de utilização da tecnologia da informação. Foi também criada e proposta, uma política de segurança da informação inicial elaborada através de toda a análise realizada na organização.

\section{RESULTADOS}

Neste capítulo apresenta-se uma visão geral dos resultados no desenvolvimento deste trabalho. Abaixo é apresentado o gráfico de riscos da UBS II, o qual foi construído com base nas informações obtidas e estudos dentro da organização, e baseado na gestão de riscos conforme CORRÊA (2014).

Para um melhor entendimento das informações são apresentados os critérios utilizados para a construção da Figura 1 - Gestão de Riscos no Quadro 1.

Quadro 1. Critérios de risco

\begin{tabular}{|l|l|}
\hline Critério & Descrição \\
\hline Insignificante & Não afeta o bom andamento da rotina, caso não esteja disponível. \\
\hline Baixo & Pouco afeta o andamento da rotina, se não estiver disponível. \\
\hline Significante & $\begin{array}{l}\text { Importante para os serviços da organização, pois os processos da mesma } \\
\text { passam por ele. }\end{array}$ \\
\hline Importante & $\begin{array}{l}\text { Todos os processos passam por ele, afeta os custos e as atividades da } \\
\text { organização. }\end{array}$ \\
\hline Crítico & A organização tem prejuízos e não executa suas atividades sem ele. \\
\hline
\end{tabular}

Fonte: Elaborado pelos autores. 
Figura 1. Gestão de Riscos

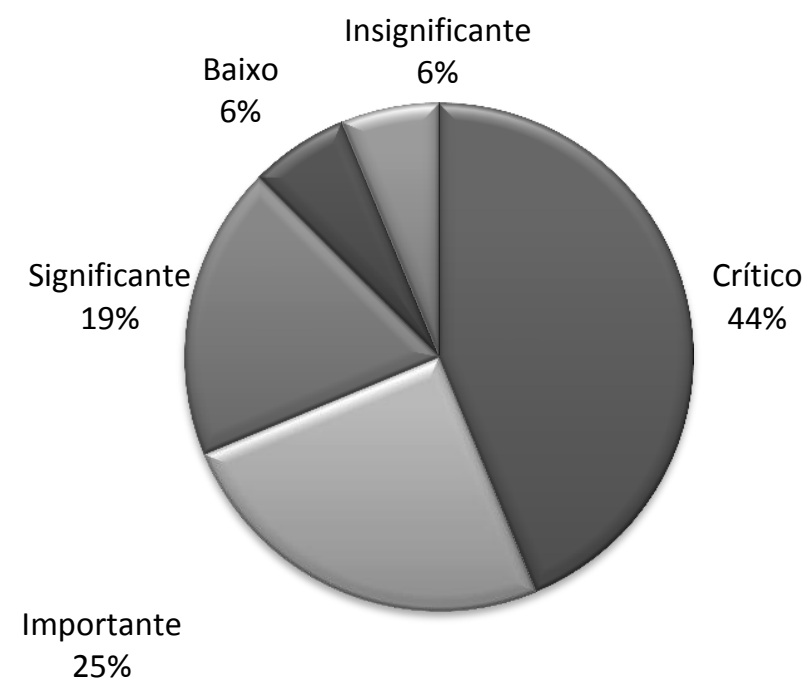

Fonte: Elaborado pelos autores.

Realizando uma análise da Figura 1 é possível verificar que em média 44\% da gestão de riscos são de nível crítico, sendo eles: Segurança de rede, Infraestrutura, Investimento na TI, Backup de dados, Sistemas, Segurança da Informação, Controle de acesso. Ainda, 25\% da gestão de riscos são de nível importante, sendo eles: Treinamentos, Documentação, Funcionários na área de TI, Política de segurança. Já outros $19 \%$ da gestão de riscos é de nível significante: Testes, Coordenação e Experiência, Controles e análises periódicos. Tem-se ainda $6 \%$ da gestão de riscos é de nível baixo: Registro de chamada (ordens de serviços). E finalmente $6 \%$ da gestão de riscos é de nível insignificante: Cotação de equipamentos de TI.

Analisando as informações obtidas na elaboração do gráfico de gestão de riscos deste estudo, comprova-se a necessidade de mudanças no setor de TI. De forma, que se forem aplicadas e seguidas às orientações demonstradas, através do uso de normas e procedimentos, os riscos podem ser diminuídos consideravelmente. Conforme a organização foi citada no decorrer do estudo, fica visível que a UBS II se encontra exposta em relação a segurança da informação, tanto externamente, quanto internamente.

A proposta da implantação de uma infraestrutura de TI completa, tem como o principal objetivo solucionar ou amenizar esses riscos a zero, fornecendo segurança da informação a UBS II contra perdas de dados e ataques; com controle de acessos, gerenciamento das atividades e serviços, monitoramento das atividades dos colaboradores, monitoramento da rede, implantações de sistemas, melhora na eficiência dos já em uso, e a criação de uma gestão de Backup eficiente e segura. Através dessas ferramentas e funções poderá ser aplicado medidas de segurança adequadas. Esta infraestrutura trará melhorias não só no setor de TI, mas a organização como um todo.

De forma geral, este estudo contribuirá na organização para que haja uma conscientização da importância do setor de $\mathrm{TI}$, onde zela pela segurança da organização e da proteção de um dos bens mais valioso dela, a informação. Além de prover segurança à informação da UBS II, acarretará em um melhor desempenho e controle dos serviços e atividades realizadas, onde até o momento se encontram desorganizados e confusos. 


\section{DISCUSSÃO}

Devido a grande importância e valor dos ativos de informação da organização, é fundamental tratá-los e protegê-los adequadamente. Sendo a informação o fator essencial da organização, este estudo viu a necessidade e importância de propor melhorias, após analisar a criticidade e vulnerabilidades apresentadas no ambiente.

Risco é a probabilidade de que as vulnerabilidades sejam exploradas pelas ameaças existentes, danificando ou ocasionando perdas aos ativos e acarretando prejuízos aos negócios da organização, conforme a CERT BR (2005).

Já o ativo de informação, conforme ABNT NBR ISO/IEC 27002, é qualquer elemento de valor para a organização que manipula, processa, armazena, transporta ou descarta a informação, incluindo a informação em si.

A UBS II não gerencia os riscos de segurança da informação aos quais está exposto, carece de aperfeiçoar sua infraestrutura computacional e a segurança de suas informações. Após o levantamento da gestão de riscos foi possível identificar os problemas presentes na UBS II, tais como, número reduzido de funcionários de $\mathrm{TI}$, falta de treinamento, falta de experiência e coordenação, ausência de um sistema centralizado, ambiente mal estruturado tecnicamente, ausência de uma infraestrutura estruturada, equipamentos, métricas, e cópia de segurança dos dados.

Os controles da norma ABNT NBR ISO/IEC 27002 foram os selecionados para colaborar no auxilio deste trabalho. Abordando pontos importantes para elaboração de uma infraestrutura de TI completa e segura, mostrando a melhor forma de se realizar um serviço ou atividade. Os controles da norma se adequaram perfeitamente com o foco do estudo de caso, e assim através das deficiências no setor de TI da UBS II eles foram sendo utilizados para ajudar a propor uma melhor segurança da informação à organização. Atribuindo soluções como implantação de sistemas, cabeamento estruturado, investimento em equipamentos e instalações (Firewall, Nobreaks, Servidores, Softwares...), e um sistema de backup dos dados.

Ainda com as normas da ABNT NBR ISO/IEC 27002, verificaram-se outros pontos sobre os quais é possível atuar para melhorar ainda mais a segurança. Um primeiro ponto seria a criação de uma política de uso dos recursos da organização para os colaboradores, sendo de extrema importância, pois muitos incidentes acabam ocorrendo através de descuidos dos mesmos. Então, foi elaborada uma versão inicial de política de segurança da informação para a UBS II, especificando as responsabilidades dentro do setor de $\mathrm{TI}$, de todos os colaboradores da organização, proteção contra softwares maliciosos, acesso à internet, e infrações puníveis caso haja violações. Por ser apenas uma política inicial para a organização, buscou ser objetiva e simples; devendo ser atualizada e elaborada uma versão completa futuramente.

Outro ponto importante, de acordo com um modelo básico de documentação de rede e infraestrutura de MENDES (2009), foi possível elaborar um modelo de documentação básico para a organização. Onde se deve mantem constantemente atualizada, e possivelmente realizar reajustes e aprimoramentos no modelo. Esta documentação servirá para identificar e facilitar o gerenciamento da rede e do ambiente de TI da UBS II.

\section{CONCLUSÃO}

Segundo a norma ABNT NBR ISO/IEC 27002, a gestão de continuidade do negócio tem como objetivo, impedir a interrupção das atividades do negócio e proteger os processos críticos contra efeitos de falhas ou desastres significativos, e assegurar que a sua retomada ocorra em tempo hábil.

A TI sempre que acessível e alinhada às operações da organização, auxiliará de forma mais ativa, melhorando a integração de todos os setores, e solucionando situações do dia a dia. Por isso, o acompanhamento dos processos deve ser constante, para aprimorar o ambiente de $\mathrm{TI}$ 
sempre que necessitar, não o deixando ficar obsoleto em relação às recentes ameaças que surgem.

De modo geral, tendo o embasamento teórico a proposta da norma ABNT NBR ISO/IEC 27002, o estudo contribuirá para uma conscientização dentro da organização sobre a importância da TI, abordando melhorias significativas na infraestrutura. Assim, aplicando um nível de segurança as informações, melhorando o gerenciamento dos equipamentos, da organização, dos processos organizacionais e dos colaboradores; alinhando a TI com os processos da organização.

Este trabalho será apresentado à organização como uma proposta, analisando o trabalho desenvolvido, e destacando a importância da sua implantação. Agora, a organização possui um quadro mais bem definido sobre sua situação, onde possibilita a mesma de uma evolução coordenada. O passo dado com este trabalho foi inicial, mas é esperado que possa marcar o início de uma transformação, sendo uma nova fase na saúde da segurança da informação da UBS II.

\section{REFERÊNCIAS}

ABNT - Associação Brasileira de Normas Técnicas. ABNT NBR ISO/IEC 27002. Tecnologia da informação - Técnicas de segurança - Código de prática para a gestão de segurança da informação. ABNT, 2013.

CARVALHO, Flávio. Empresas Brasileiras pretendem investir até $\mathrm{R} \$ 110$ mil em Segurança da informação neste ano. Disponível em: <http://convergecom.com.br/tiinside/04/10/2013/empresas-brasileiras-pretendeminvestir-ate-r110-mil-seguranca-informacao-neste-ano/\#.Ulm2JtKsiSo>. Acesso em: 03 mar. 2017.

CERT.br -- Centro de Estudos, Resposta e Tratamento de Incidentes de Segurança no Brasil, Práticas de Segurança para Administradores de Redes Internet, 05 de JUN de 2005. Disponível em: <https://www.cert.br/docs/seg-adm-redes/seg-admredes.html\#subsubsec4.12.1>. Acesso em: 15 abr. 2017.

CORRÊA, Renata Michele. UM ESTUdO DE CASO SOBRE A GESTÃO DA SEGURANÇA DA INFORMAÇÃO EM UMA EMPRESA PRIVADA. Disponível em: <http://docplayer.com.br/761292Renata-michele-correa-um-estudo-de-caso-sobre-a-gestao-da-seguranca-da-informacao-em-umaempresa-privada.html>. Acesso em: 20 abr. 2017.

DANTAS, Marcus Leal. SEGURANÇA DA INFORMAÇÃO: UMA ABORDAGEM FOCADA EM GESTÃO DE RISCOS. Disponível em: <http://www.marcusdantas.com.br/files/seguranca_informacao.pdf> Acesso em: 03 mar. 2017.

MENDES, Silvio. DOCUMENTAÇAO DA INFRA-ESTRUTURA DE REDE.

Disponível em: <http://www.silvio.me/wp-content/uploads/2009/07/Modelo-DocumentacaoRede.pdf >. Acesso em: 12 mai. 2017. 